\title{
Exploration and Validation of the Performance of Hemoglobin A1c in Detecting Diabetes in Community- Dwellers With Hypertension
}

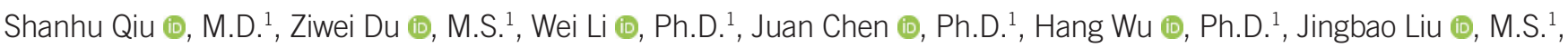

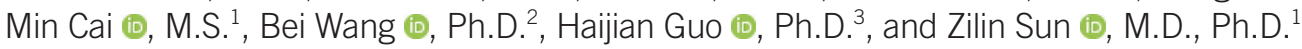

${ }^{1}$ Department of Endocrinology, Zhongda Hospital, Institute of Diabetes, School of Medicine, Southeast University, Nanjing, China; ${ }^{2}$ School of Public Health, Southeast University, Nanjing, China; ${ }^{3}$ Department of Integrated Services, Jiangsu Provincial Center for Disease Control and Prevention, Nanjing, China

Background: Diabetes can complicate hypertension management by increasing the risk of cardiovascular disease (CVD) and all-cause mortality. Studies targeting diabetes detection in hypertensive individuals demonstrating an increased risk of diabetes are lacking. We aimed to assess the performance of hemoglobin $\mathrm{A}_{1 \mathrm{c}}\left(\mathrm{HbA}_{1 \mathrm{c}}\right)$ and its cut-off point in detecting diabetes in the abovementioned population.

Methods: Data from 4,096 community-dwellers with hypertension but without known diabetes were obtained from the Study on Evaluation of iNnovated Screening tools and determInation of optimal diagnostic cut-off points for type 2 diaBetes in Chinese muLti-Ethnic (SENSIBLE) study; these data were randomly split into exploration (70\% of the sample) and internal validation (the remaining 30\%) datasets. The optimal $\mathrm{HbA}_{1 \mathrm{c}}$ cut-off point was derived from the exploration dataset and externally validated using another dataset from 2,431 hypertensive individuals. The oral glucose tolerance test was considered the goldstandard for confirming diabetes.

Results: The areas under the ROC curves for $\mathrm{HbA}_{1 \mathrm{c}}$ to detect diabetes were 0.842, 0.832, and 0.829 for the exploration, internal validation, and external validation datasets, respectively. An optimal $\mathrm{HbA}_{1 \mathrm{c}}$ cut-off point of $5.8 \%$ (40 mmol/mol) yielded a sensitivity of $76.2 \%$ and a specificity of $74.5 \%$. Individuals who were not diagnosed as having diabetes by $\mathrm{HbA}_{1 \mathrm{c}}$ at 5.8\% (40 mmol/mol) had a lower 10-year CVD risk score than those diagnosed as having diabetes $(P=0.01) . \mathrm{HbA}_{1 \mathrm{c}} \leq 5.1 \%(32 \mathrm{mmol} / \mathrm{mol})$ and $\geq 6.4 \%(46 \mathrm{mmol} / \mathrm{mol})$ could indicate the absence and presence of diabetes, respectively.

Conclusions: $\mathrm{HbA}_{1 c}$ could detect diabetes effectively in community-dwellers with hypertension.

Key Words: Hemoglobin $A_{1 c}$, Diabetes, Hypertension, Detection, Cut-off, Community-dwellers, Cardiovascular disease
Received: December 19, 2019

Revision received: February 27, 2020

Accepted: May 27, 2020

Corresponding author: Zilin Sun, M.D., Ph.D. Department of Endocrinology, Zhongda Hospital, Institute of Diabetes, School of Medicine, Southeast University, Dingjiaqiao Street No. 87, Nanjing 210009, China

Tel: +86-025-83262813

Fax: +86-025-83262609

E-mail: sunzilin1963@126.com

\section{INTRODUCTION}

As a major risk factor for cardiovascular disease (CVD) and allcause mortality, hypertension has become a global health challenge [1]. The latest national survey from China has shown that the prevalence of hypertension is approximately $45 \%$ in adults aged 35-75 years [2]. Diabetes is a well-recognized contributing factor for hypertension [3], and its presence can complicate hypertension management $[4,5]$. This is partly reflected by data demonstrating that individuals with both hypertension and dia- 
betes exhibit a markedly increased risk of CVD or all-cause mortality than those with only hypertension [6, 7]. Previous studies have shown that hypertension is associated with a higher risk of diabetes compared with normal blood pressure [8, 9]. Therefore, early detection of diabetes among hypertensive individuals is of clinical importance, as it would enable the implementation of efficient interventions in a timely manner. However, to date, no study has focused on detecting diabetes in this population.

Hemoglobin $\mathrm{A}_{1 \mathrm{c}}\left(\mathrm{HbA}_{1 \mathrm{c}}\right)$ reflects the average blood glucose level in the preceding 8-12 weeks and can be measured without fasting; the American Diabetes Association (ADA) recommended using $\mathrm{HbA}_{1 \mathrm{c}}$ to detect diabetes or individuals at risk for diabetes in 2010, after years of debate [10]. Several studies have investigated the performance of $\mathrm{HbA}_{1 \mathrm{c}}$ in detecting undiagnosed diabetes across a spectrum of diverse populations such as general adults [11, 12], gestational women [13], and children [14]. However, its performance among hypertensive individuals and how to better facilitate its use in this population (e.g., how to rule out diabetes) remain largely unknown. Current ADA guidelines recommend an $\mathrm{HbA}_{1 \mathrm{c}}$ cut-off point of $6.5 \%$ (48 $\left.\mathrm{mmol} / \mathrm{mol}\right)$ for diagnosing diabetes [10]; however, it is unclear whether this cutoff point is suitable for hypertensive individuals.

Therefore, we aimed to evaluate the performance of $\mathrm{HbA}_{1 \mathrm{c}}$ in diabetes screening, as well as to identify its optimal cut-off point for community-dwellers with hypertension. We also compared the diagnostic efficacy of the newly derived $\mathrm{HbA}_{1 c}$ cut-off point with that of the recommended $6.5 \%$ (48 $\mathrm{mmol} / \mathrm{mol}$ ) cut-off point [10], as well as the differences in cardiometabolic risk profiles between individuals who were not diagnosed as having diabetes and those who were diagnosed as having diabetes using the newly derived $\mathrm{HbA}_{1 \mathrm{c}}$ cut-off point.

\section{MATERIALS AND METHODS}

\section{Study population}

All study individuals were from the Study on Evaluation of iNnovated Screening tools and determInation of optimal diagnostic cut-off points for type 2 diaBetes in Chinese muLti-Ethnic (SENSIBLE) study [15] and the SENSIBLE-Addition study (see below). In the present study, which had a prospective cross-sectional design, individuals who were 20-70 years old and diagnosed as having hypertension, but free of known diabetes, were selected [15]. Eligible individuals from the SENSIBLE study were split randomly into two groups: one (70\% of the sample) to assess the performance of $\mathrm{HbA}_{1 \mathrm{c}}$ in detecting diabetes (the exploration dataset) and another (the remaining 30\%) for internal validation (the internal validation dataset). The SENSIBLE-Addition study (the external validation dataset) was used for external validation. The protocols for the SENSIBLE and SENSIBLE-Addition studies were approved by the Ethical Review Committees of Zhongda Hospital, Southeast University, Nanjing, China and the other 16 participating hospitals/institutes in China. All individuals provided written informed consent prior to participation. This study followed the STARD guidelines [16].

The anthropometric and biochemical characteristics of individuals in the exploration ( $N=2,868)$, internal validation ( $N=1,228)$, and external validation $(\mathrm{N}=2,431)$ datasets are shown in Table 1. Compared with the exploration and internal validation datasets, individuals in the external validation dataset were younger, had higher body mass index (BMI) and waist circumference (WC) values, and showed lower systolic blood pressure (SBP), diastolic blood pressure (DBP), total cholesterol (TC), and lowdensity lipoprotein cholesterol $(L D L-C)$ levels (all $P<0.05)$. The prevalence of undiagnosed diabetes among these three cohorts were $14.2 \%, 14.5 \%$, and $17.5 \%$, respectively.

\section{SENSIBLE study}

A cross-sectional survey was conducted in seven provinces in China from November 1st, 2016 to June 30th, 2017 [15]. An age- and sex-stratified, random sample of 13,620 communitydwellers who had lived $\geq 5$ years in their current residence was invited, and 12,017 of the invited individuals participated in this study, with 4,096 eligible for analysis (Fig. 1A).

All individuals were asked to complete a questionnaire containing information regarding their sociodemographic characteristics, lifestyle factors, and medical history. Body weight, height, and WC were measured using standard methods, and BMI was calculated. Blood pressure was measured using an electronic sphygmomanometer (YE680E, Jiangsu Yuyue Medical Equipment Inc., Nanjing, Jiangsu, China) [15]. All individuals were asked to fast for at least 10 hours before receiving a $75 \mathrm{~g}$ standardized oral glucose tolerance test (OGTT), for which venous blood samples (5 mL EDTA tubes) were drawn before and two hrs post glucose loading. Blood samples were centrifuged at $1,000-1,200 \times g$ for 5 minutes at room temperature (around $22-25^{\circ} \mathrm{C}$ ) within 30 minutes of collection and shipped at $4^{\circ} \mathrm{C}$ by air to Nanjing Adicon Clinical Laboratories, Nanjing, China. Fasting plasma glucose (FPG), 2-hours postprandial glucose (2h$P G), T C$, triglycerides (TG), high-density lipoprotein cholesterol (HDL-C), and LDL-C levels were measured using the automated analyzer, Synchron LX-20 (Beckman Coulter Inc., Fullerton, CA, USA). Specifically, the intra-assay and inter-assay coefficients of 
Qiu S, et al.

$\mathrm{HbA}_{1 \mathrm{c}}$ to detect diabetes in hypertensive people

Table 1. Characteristics of the individuals in the different study cohorts

\begin{tabular}{|c|c|c|c|c|}
\hline & $\begin{array}{l}\text { Exploration population } \\
\text { (cohort 1) }\end{array}$ & $\begin{array}{l}\text { Internal validation } \\
\quad \text { (cohort 2) }\end{array}$ & $\begin{array}{l}\text { External validation } \\
\text { (cohort 3) }\end{array}$ & $P$ \\
\hline Individuals, N & 2,868 & 1,228 & $2,431^{*}$ & \\
\hline Male, N (\%) & $1,120(39.1)$ & $476(38.8)$ & $1,078(44.3)$ & $<0.001$ \\
\hline Smoker, N (\%) & $643(22.4)$ & $258(21.0)$ & $641(26.4)$ & $<0.001$ \\
\hline Known hypertension, $\mathrm{N}(\%)$ & $1,254(43.7)$ & $556(45.3)$ & $1,284(52.8)$ & $<0.001$ \\
\hline Age (yr) & $57(50,63)$ & $58(50,64)$ & $55(49,61)$ & 0.0001 \\
\hline BMI $\left(\mathrm{kg} / \mathrm{m}^{2}\right)$ & $25.6(23.1,28.1)$ & $25.6(23.1,28.0)$ & $26.3(24.1,28.4)$ & 0.0001 \\
\hline WC (cm) & $85(78,92)$ & $84(78,92)$ & $88(81,93)$ & 0.0001 \\
\hline SBP (mmHg) & $148(140,160)$ & $147(140,160)$ & $147(140,158)$ & 0.03 \\
\hline $\mathrm{DBP}(\mathrm{mmHg})$ & $91(84,98)$ & $91(83,98)$ & $90(84,96)$ & 0.0007 \\
\hline $\mathrm{FPG}(\mathrm{mmol} / \mathrm{L})$ & $5.6(5.2,6.1)$ & $5.5(5.1,6.0)$ & $5.8(5.5,6.3)$ & 0.0001 \\
\hline 2h-PG (mmol/L) & $7.1(5.7,8.9)$ & $7.0(5.7,8.7)$ & $7.4(6.2,9.1)$ & 0.0001 \\
\hline$H b A_{1 c}(\%)$ & $5.5(5.2,5.9)$ & $5.4(4.7,6.2)$ & $5.5(5.2,5.8)$ & 0.0001 \\
\hline $\mathrm{HbA}(\mathrm{mmol} / \mathrm{mol})$ & $37(33,41)$ & $36(28,44)$ & $37(33,40)$ & 0.0001 \\
\hline TC (mmol/L) & $5.4(4.7,6.2)$ & $5.4(4.7,6.2)$ & $4.9(4.3,5.5)$ & 0.0001 \\
\hline $\mathrm{TG}(\mathrm{mmol} / \mathrm{L})$ & $1.4(1.0,2.1)$ & $1.3(0.9,2.0)$ & $1.5(1.0,2.3)$ & 0.0001 \\
\hline HDL-c (mmol/L) & $1.5(1.3,1.8)$ & $1.5(1.3,1.8)$ & $1.5(1.3,1.7)$ & 0.0001 \\
\hline LDL-c (mmol/L) & $3.2(2.6,3.7)$ & $3.1(2.6,3.6)$ & $2.7(2.3,3.2)$ & 0.0001 \\
\hline $\mathrm{Cr}(\mu \mathrm{mol} / \mathrm{L})$ & $63(53,74)$ & $63(53,74)$ & $64(55,75)$ & 0.01 \\
\hline
\end{tabular}

Data are presented as median (interquartile range) or, where stated, as number and percentage.

*Three individuals did not provide DBP data.

Abbreviations: BMI, body mass index; WC, waist circumference; SBP, systolic blood pressure; DBP, diastolic blood pressure; FPG, fasting plasma glucose; 2h-PG, 2-hr postprandial glucose; $\mathrm{HbA}_{1 c}$, hemoglobin $\mathrm{A}_{1 \mathrm{c}}$; TC, total cholesterol; TG, triglycerides; HDL-c, high-density lipoprotein cholesterol; LDL-c, low-density lipoprotein cholesterol; $\mathrm{Cr}$, creatine.
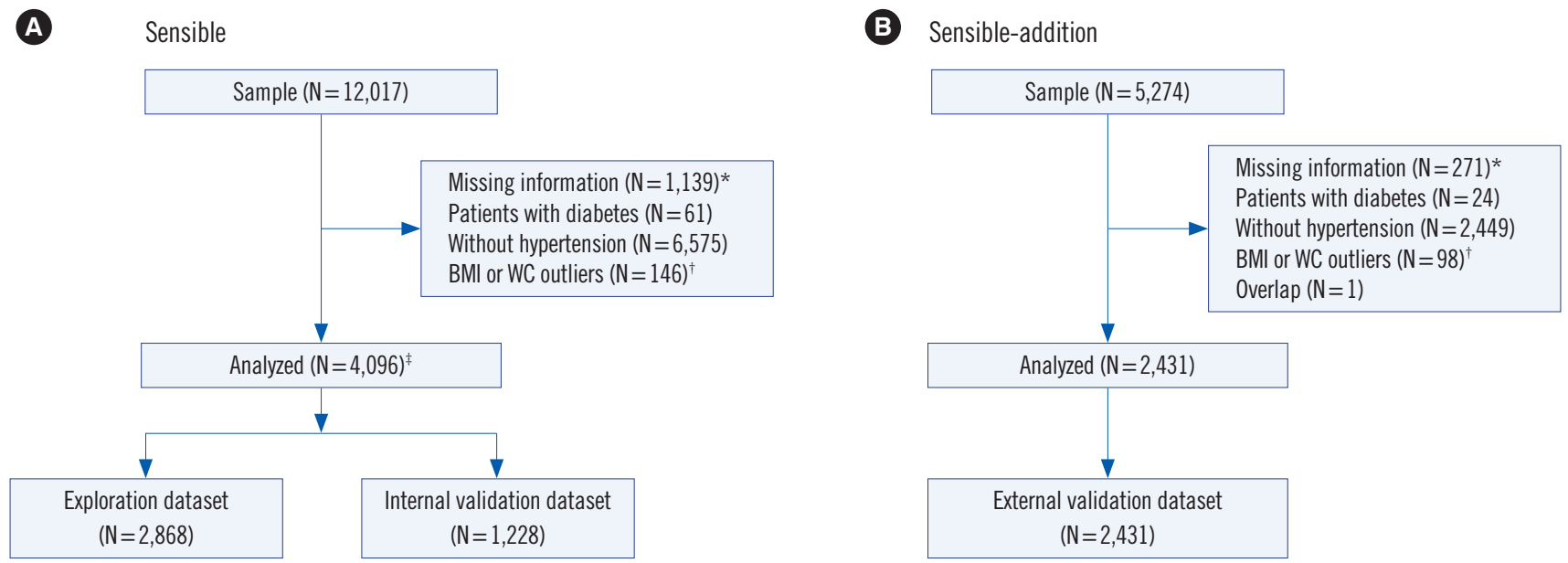

Fig. 1. Participant selection process for (A) the SENSIBLE study and (B) the SENSIBLE-Addition study. *indicates missing information for age, BMI, WC, smoking, glycemic biomarkers, and lipid profiles; ${ }^{\dagger}$ Outliers indicate data $>99$ th percentile or < 1 st percentile of the dataset; ‡Data for these individuals were randomly split into the exploration dataset (70\% of the sample) and the internal validation dataset (the remaining 30\%).

Abbreviations: SENSIBLE, Study on Evaluation of iNnovated Screening tools and determInation of optimal diagnostic cut-off points for type 2 diaBetes in Chinese muLti-Ethnic; BMI, body mass index; WC, waist circumference. 
variation for blood glucose were both $\leq 3 \%$. $\mathrm{HbA}_{1 \mathrm{c}}$ was determined with a D-10 Hemoglobin Analyzer (Bio-Rad Inc., Hercules, CA, USA) using an HPLC-based method. This method was certified by the National Glycohemoglobin Standardization Program and standardized to the Diabetes Control and Complications Trial assay approach [17]. In this study, the intra-assay coefficient of variation for $\mathrm{HbA}_{1 \mathrm{c}}$ was $0.81-1.67 \%$, and the interassay coefficient of variation for $\mathrm{HbA}_{1 \mathrm{c}}$ was $1.35-2.27 \%$.

\section{SENSIBLE-Addition study}

This study had a design similar to that of the SENSIBLE study; however, it was conducted in the Jiangsu Province from April 15th, 2017 to July 31st, 2017, together with liver function measurements and acquisition of additional information regarding health care needs. In total, 5,274 individuals completed a questionnaire survey and underwent an OGTT. Of these, 2,431 were eligible for the external validation dataset (Fig. 1B). Laboratory markers, including FPG, 2h-PG, HbA 1 c, TC, TG, HDL-c, and LDL-c were analyzed using the same approaches as outlined for the SENSIBLE study.

\section{Definitions}

Hypertension was defined as SBP $\geq 140 \mathrm{mmHg}$ or DBP $\geq 90$ $\mathrm{mmHg}$ on average, a self-reported history of hypertension, or a self-reported use of antihypertensive drugs [2]. Diabetes was diagnosed based on the 1999 WHO criteria: FPG $\geq 7.0 \mathrm{mmol} / \mathrm{L}$, $2 \mathrm{~h}-\mathrm{PG} \geq 11.1 \mathrm{mmol} / \mathrm{L}$, or both [18]. The 10-year risk score of CVD was calculated according to the Framingham Risk Score for predicting CVD [19]. True-positive cases were defined as individuals with confirmed diabetes based on the 1999 WHO criteria who could be identified as having diabetes by $\mathrm{HbA}_{1 c}$ at the derived cut-off point, while false-negative cases were defined as individuals with confirmed diabetes based on the 1999 WHO criteria who could not be identified as having diabetes by $\mathrm{HbA}_{1 c}$ at the derived cut-off point. Screen-positive cases were defined as individuals with $\mathrm{HbA}_{1 \mathrm{c}}$ above the derived cut-off point, while screen-negative cases were defined as individuals with $\mathrm{HbA}_{1 c}$ below the derived cut-off point.

\section{Statistical analysis}

Statistical analyses were conducted using STATA version 14.0 (StataCorp LP, College Station, TX, USA). As the continuous variables were non-normally distributed (assessed by Shapiro-Wilk normality test), they are presented as the median (interquartile range). Categorical variables are expressed as a number (proportion). Differences in continuous and categorical variables were determined using the Kruskal-Wallis test (at least three groups) or Wilcoxon rank-sum test (two groups) and the Chi-squared test, respectively. The diagnostic efficacy of $\mathrm{HbA}_{1 c}$ in detecting diabetes was evaluated using the area under the ROC (AUROC) curve. The optimal $\mathrm{HbA}_{1 \mathrm{c}}$ cut-off point was determined by minimizing the $\left[(1-\text { sensitivity })^{2}+(1-\text { specificity })^{2}\right]$ score, which represents the maximum sum of the sensitivity and specificity [20]. Sensitivities, specificities, and AUROCs were compared using the methods proposed by Altman and Bland [21]. Moreover, based on the methods described by Lu, et al. [22], the $\mathrm{HbA}_{10}$ value at the 2.5th percentile was determined as the cut-off point for ruling out diabetes, while that at the 97.5th percentile was determined as the cut-off point for ruling in diabetes. Subgroup analyses of hypertension awareness (known vs unknown), age $(<50,50-60$, vs $60-70$ years), and exercise status (regular vs irregular) and sensitivity analyses, excluding individuals using statins and those with anemia, were performed to assess the robustness of the primary results. To increase the data analysis statistical power, a meta-analytical approach using a random-effects model, as well as a combination of all three cohorts at the individual patient level, was used. All statistical tests were twosided, with $P<0.05$ considered statistically significant.

\section{RESULTS}

\section{Performance of $\mathrm{HbA}_{1 \mathrm{c}}$ in detecting diabetes}

The performance of $\mathrm{HbA}_{1 \mathrm{c}}$ in detecting diabetes among the exploration population is presented in Table 2. Increasing the $\mathrm{HbA}_{1 \mathrm{c}}$ cut-off point resulted in decreased sensitivity and negative predictive values, but increased specificity and positive predictive values. An $\mathrm{HbA}_{1 \mathrm{c}}$ cut-off point of $5.8 \%$ (40 $\mathrm{mmol} / \mathrm{mol}$ ) yielded the best trade-off for sensitivity and specificity, showing a sensitivity of $76.2 \%$ and a specificity of $74.5 \%$. Using the derived $5.8 \%\left(40 \mathrm{mmol} / \mathrm{mol}\right.$ ) $\mathrm{HbA}_{1 \mathrm{c}}$ cut-off point for detecting diabetes, the internal validation dataset showed sensitivity and specificity values similar to those of the exploration dataset (both $P>0.70$; Table 2). However, when the suggested diagnostic $\mathrm{HbA}_{1 \mathrm{c}}$ cut-off point of $6.5 \%$ (48 mmol/mol) [10] was applied, the sensitivity was only $44.2 \%$ in the exploration dataset and further decreased to $39.9 \%$ in the internal validation dataset and $33.1 \%$ in the external validation dataset.

The AUROCs of $\mathrm{HbA}_{1 \mathrm{c}}$ in detecting undiagnosed diabetes were 0.842 (95\% confidence interval [Cl], 0.819-0.865) in the exploration dataset (Fig. 2A), $0.832(95 \% \mathrm{Cl}, 0.794-0.870)$ in the internal validation dataset (Fig. 2B), and $0.829(95 \% \mathrm{Cl}$, $0.806-0.853$ ) in the external validation dataset (Fig. $2 \mathrm{C}$ ). The 
Qiu S, et al.

$\mathrm{HbA}_{1 \mathrm{c}}$ to detect diabetes in hypertensive people

Table 2. Performance of hemoglobin $A_{1 c}$ in the different study cohorts*

\begin{tabular}{lllll}
\hline $\mathrm{HbA}_{\mathrm{lc}}$ cut-off & Sensitivity (\%) & Specificity (\%) & PPV (\%) & NPV (\%) \\
\hline Exploration dataset & & & & \\
$5.6 \%(38 \mathrm{mmol} / \mathrm{mol})$ & $87.0(83.3-90.1)$ & $57.2(55.2-59.2)$ & $25.2(22.9-27.5)$ & $96.4(95.3-97.3)$ \\
$5.7 \%(39 \mathrm{mmol} / \mathrm{mol})$ & $83.1(79.0-86.6)$ & $66.6(64.7-68.5)$ & $29.1(26.5-31.8)$ & $96.0(94.9-96.8)$ \\
$5.8 \%(40 \mathrm{mmol} / \mathrm{mol})$ & $76.2(71.7-80.2)$ & $74.5(72.7-76.2)$ & $33.0(30.0-36.2)$ & $95.0(93.9-95.9)$ \\
$5.9 \%(41 \mathrm{mmol} / \mathrm{mol})$ & $71.0(66.3-75.4)$ & $81.3(79.7-82.8)$ & $38.5(35.0-42.1)$ & $94.4(93.4-95.4)$ \\
$6.0 \%(42 \mathrm{mmol} / \mathrm{mol})$ & $66.6(61.8-71.2)$ & $85.6(84.1-86.9)$ & $43.3(39.4-47.3)$ & $93.9(92.9-94.9)$ \\
$6.1 \%(43 \mathrm{mmol} / \mathrm{mol})$ & $60.2(55.3-65.0)$ & $90.2(89.0-91.4)$ & $50.4(45.9-54.9)$ & $93.2(92.1-94.2)$ \\
$6.5 \%(48 \mathrm{mmol} / \mathrm{mol})$ & $44.2(39.3-49.2)$ & $98.1(97.4-98.6)$ & $78.9(73.1-84.1)$ & $91.4(90.3-92.4)$ \\
Internal validation dataset & & & & $34.2(29.5-39.1)$ \\
$5.8 \%(48 \mathrm{mmol} / \mathrm{mol})$ & $76.4(69.5-82.4)$ & $75.1(72.3-77.6)$ & & $94.9(93.2-96.3)$ \\
External validation dataset & & & & $91.2(79.4-82.9)$ \\
$5.8 \%(48 \mathrm{mmol} / \mathrm{mol})$ & $68.8(64.1-73.2)$ & & & $92.5(91.1-93.6)$ \\
\hline
\end{tabular}

Data are presented as percentage (95\% confidence interval).

*The Study on Evaluation of iNnovated Screening tools and determInation of optimal diagnostic cut-off points for type 2 diaBetes in Chinese muLti-Ethnic (SENSIBLE) data were split randomly into the exploration dataset (70\% of the sample) and the internal validation dataset (the remaining $30 \%$ ).

Abbreviations: $\mathrm{HbA}_{1 c}$, hemoglobin $\mathrm{A}_{1 c}$; PPV, positive predictive value; NPV, negative predictive value.

A
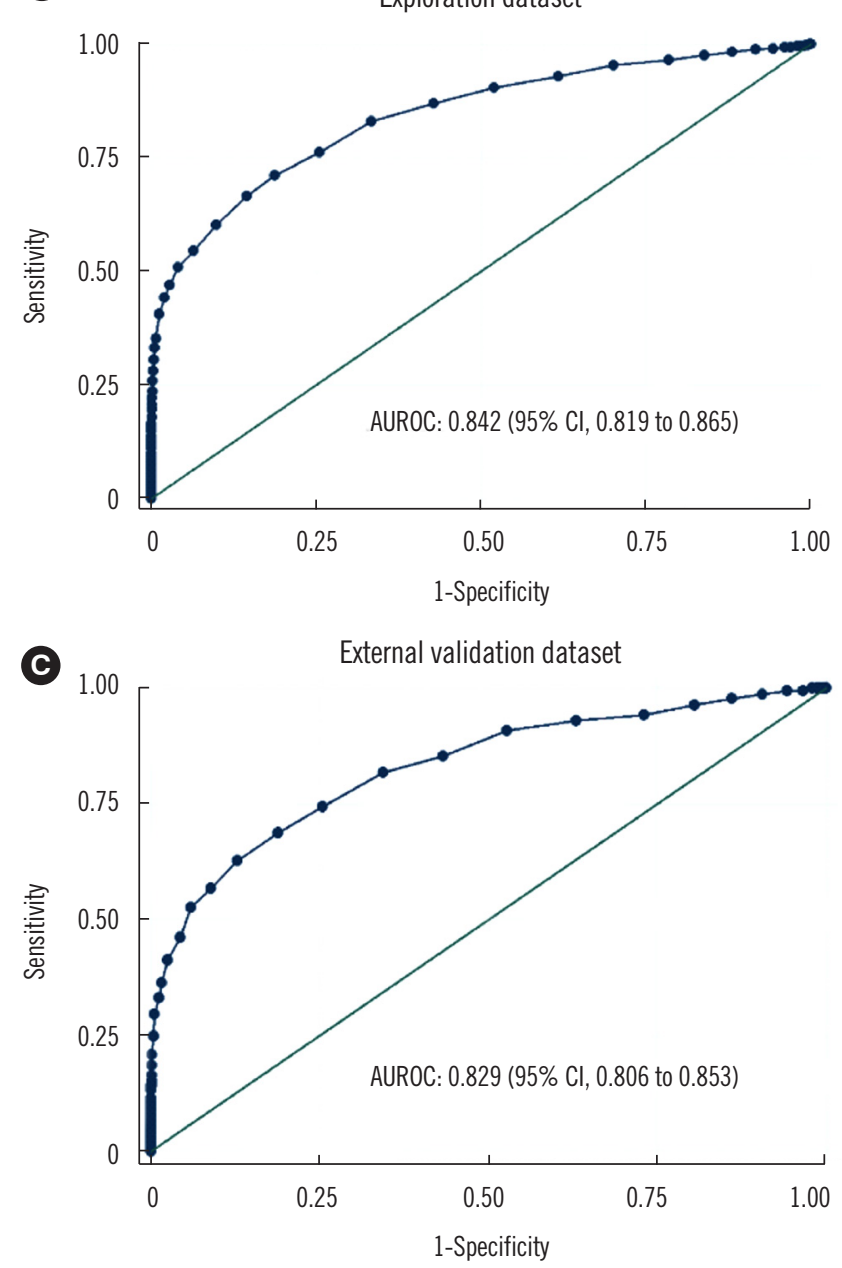

B

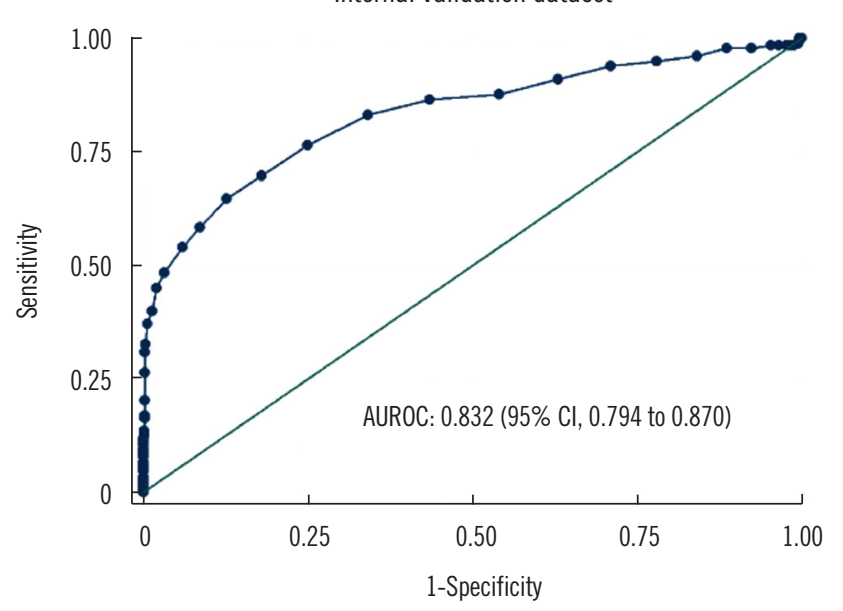

Fig. 2. ROC curves for hemoglobin $A_{1 c}$ in the different study cohorts. (A) exploration dataset. (B) internal validation dataset. (C) external validation dataset.

Abbreviations: AUROC, area under the ROC curve; $\mathrm{Cl}$, confidence interval. 
Table 3. AUROC curve of $\mathrm{HbA}_{1 \mathrm{c}}$ by subgroup

\begin{tabular}{lccc}
\hline \multirow{2}{*}{\begin{tabular}{c} 
Subgroups \\
\cline { 2 - 4 }
\end{tabular}} & $\begin{array}{c}\text { Exploration } \\
\text { dataset }\end{array}$ & $\begin{array}{c}\text { AUROC (95\% CI) } \\
\text { Internal validation } \\
\text { dataset }\end{array}$ & $\begin{array}{c}\text { External validation } \\
\text { dataset }\end{array}$ \\
\hline $\begin{array}{l}\text { Sex-based groups } \\
\text { Male }\end{array}$ & $0.821(0.782-0.859)$ & $0.784(0.721-0.848)$ & $0.827(0.792-0.862)$ \\
Female & $0.859(0.831-0.887)$ & $0.881(0.842-0.921)$ & $0.832(0.800-0.864)$ \\
Hypertension awareness groups & & \\
Known & $0.838(0.805-0.871)$ & $0.811(0.758-0.864)$ & $0.838(0.809-0.867)$ \\
Unknown & $0.844(0.811-0.877)$ & $0.849(0.792-0.905)$ & $0.810(0.770-0.850)$ \\
Age-based groups & & \\
$<50$ yr & $0.849(0.784-0.913)$ & $0.735(0.608-0.863)$ & $0.865(0.822-0.908)$ \\
$50-60$ yr & $0.843(0.803-0.883)$ & $0.852(0.789-0.915)$ & $0.811(0.773-0.850)$ \\
$60-70$ yr & $0.825(0.792-0.859)$ & $0.840(0.791-0.889)$ & $0.823(0.782-0.863)$ \\
Regular exercise groups* & & \\
Yes & $0.839(0.811-0.876)$ & $0.854(0.802-0.905)$ & $0.857(0.818-0.896)$ \\
No & $0.839(0.806-0.873)$ & $0.817(0.763-0.871)$ & $0.816(0.787-0.845)$ \\
\hline
\end{tabular}

*This information was obtained by asking "Do you undertake regular exercise every week?"

Abbreviations: AUROC, area under the ROC curve; $\mathrm{HbA}_{1 c}$, hemoglobin $\mathrm{A}_{1 \mathrm{c}}$; $\mathrm{Cl}$, confidence interval.
AUROCs of both validation datasets were comparable to that of the exploration dataset $(P=0.66$ and 0.44 , respectively). The $\mathrm{HbA} A_{1 c}$ AUROC remained largely unchanged following the exclusion of individuals using statins or with anemia (data not shown).

Subgroup analyses showed that the HbA $\mathrm{HIC}_{1 \mathrm{C}}$ AUROC was comparable among groups stratified by hypertension awareness, age, or exercise status in the exploration and validation datasets (all $P>0.05$; Table 3). To enhance the statistical power, the AUROCs from all three cohorts were pooled using a random-effects metaanalysis model. The results indicated that there was no significant difference between women and men (0.859 vs. 0.820 , $P=0.09$ ) and between the other subgroups listed in Table 3 (all $P>0.05)$

\section{Comparisons between individuals identified as true-positive and false-negative}

As all the three cohorts used comparable survey procedures with overall identical information, they were combined to increase the statistical power for further comparisons between individuals identified as true-positive and false-negative using the derived

Table 4. Characteristics of true-positive versus false-negative cases and screen-positive versus screen-negative cases in all three datasets

\begin{tabular}{|c|c|c|c|c|c|c|}
\hline & Individu & with confirmed dia & & Individuals wh & underwent diabetes & reening* \\
\hline & $\begin{array}{l}\text { True-positive }^{\dagger} \\
\quad(\mathrm{N}=684)\end{array}$ & $\begin{array}{l}\text { False-negative }{ }^{\ddagger} \\
\quad(\mathrm{N}=254)\end{array}$ & $P$ & $\begin{array}{l}\text { Screen-positive } \\
\quad(N=2,006)\end{array}$ & $\begin{array}{l}\text { Screen-negative } \\
\quad(\mathrm{N}=4,521)\end{array}$ & $P$ \\
\hline Age (yr) & $58(52,63)$ & $55(50,63)$ & 0.05 & $58(52,64)$ & $55(49,62)$ & $<0.0001$ \\
\hline BMI $\left(\mathrm{kg} / \mathrm{m}^{2}\right)$ & $27.0(24.9,29.5)$ & $26.7(23.8,28.9)$ & 0.006 & $26.4(24.3,28.9)$ & $25.6(23.2,27.9)$ & $<0.0001$ \\
\hline WC (cm) & $90(83,96)$ & $88(80,95)$ & 0.01 & $87(80,94)$ & $85(79,92)$ & $<0.0001$ \\
\hline SBP (mmHg) & $149(140,161)$ & $151(142,163)$ & 0.26 & $148(140,160)$ & $147(140,158)$ & 0.002 \\
\hline $\mathrm{DBP}(\mathrm{mmHg})$ & $91(83,97)$ & $92(84,98)$ & 0.12 & $90(83,96)$ & $91(84,97)$ & 0.005 \\
\hline $\mathrm{FPG}(\mathrm{mmol} / \mathrm{L})$ & $7.3(6.5,8.3)$ & $6.7(5.9,7.2)$ & $<0.0001$ & $6.1(5.6,6.9)$ & $5.5(5.2,5.9)$ & $<0.0001$ \\
\hline $\mathrm{PPG}(\mathrm{mmol} / \mathrm{L})$ & $13.3(11.5,16.5)$ & $11.5(10.3,12.6)$ & $<0.0001$ & $8.8(6.8,11.9)$ & $6.8(5.6,8.1)$ & $<0.0001$ \\
\hline$H b A_{1 c}(\%)$ & $6.5(6.1,7.2)$ & $5.2(4.5,6.0)$ & $<0.001$ & $6.1(5.9,6.4)$ & $5.3(5.1,5.5)$ & $<0.0001$ \\
\hline $\mathrm{HbA} \mathrm{Alc}_{\mathrm{lc}}(\mathrm{mmol} / \mathrm{mol})$ & $48(43,55)$ & $33(26,42)$ & $<0.0001$ & $43(41,46)$ & $34(32,37)$ & $<0.0001$ \\
\hline $\mathrm{TC}(\mathrm{mmol} / \mathrm{L})$ & $5.5(4.8,6.3)$ & $5.2(4.5,6.0)$ & 0.0001 & $5.4(4.7,6.2)$ & $5.1(4.4,5.9)$ & $<0.0001$ \\
\hline $\mathrm{TG}(\mathrm{mmol} / \mathrm{L})$ & $1.9(1.3,2.8)$ & $1.8(1.2,2.7)$ & 0.16 & $1.6(1.1,2.4)$ & $1.4(0.9,2.1)$ & $<0.0001$ \\
\hline HDL-c (mmol/L) & $1.5(1.2,1.7)$ & $1.5(1.3,1.8)$ & 0.03 & $1.5(1.2,1.7)$ & $1.5(1.3,1.8)$ & $<0.0001$ \\
\hline LDL-c (mmol/L) & $3.2(2.7,3.8)$ & $2.8(2.3,3.5)$ & $<0.0001$ & $3.1(2.6,3.7)$ & $2.9(2.4,3.4)$ & $<0.0001$ \\
\hline 10 -yr CVD risk score (\%) & $26.7(18.5,39.8)$ & $24.2(16.2,36.1)$ & 0.01 & $21.1(12.4,35.9)$ & $14.3(8.5,24.5)$ & $<0.0001$ \\
\hline
\end{tabular}

Data are presented as median (interquartile range).

*Three individuals did not provide DBP data; 'True-positive cases were defined as individuals with confirmed diabetes based on the 1999 WHO criteria that were detected by $\mathrm{HbA}_{1 \mathrm{c}}$ at the derived cut-off point of $5.8 \%(40 \mathrm{mmol} / \mathrm{mol})$; ${ }^{\ddagger}$ False-negative cases were defined as individuals with confirmed diabetes based on the $1999 \mathrm{WHO}$ criteria that were not detected by $\mathrm{HbA}_{1 \mathrm{c}}$ at the derived cut-off point of $5.8 \%(40 \mathrm{mmol} / \mathrm{mol})$; ${ }^{\circledR}$ Screen-positive cases were defined as individuals with an $\mathrm{HbA}_{1 c} \geq$ the derived cut-off point of $5.8 \%(40 \mathrm{mmol} / \mathrm{mol})$; "Screen-negative cases were defined as individuals with an $\mathrm{HbA} \mathrm{A}_{1 \mathrm{c}}<\mathrm{the}$ derived cut-off point of 5.8\% (40 mmol/mol); "The 10-year risk score of CVD was calculated according to the Framingham Risk Score for predicting CVD [19]. Abbreviations: BMI, body mass index; WC, waist circumference; SBP, systolic blood pressure; DBP, diastolic blood pressure; FPG, fasting plasma glucose; PPG, post-prandial plasma glucose; $\mathrm{HbA}_{1 c}$, hemoglobin $\mathrm{A}_{1 \mathrm{c}}$; TC, total cholesterol; TG, triglycerides; HDL-c, high-density lipoprotein cholesterol; LDL-c, lowdensity lipoprotein cholesterol; CVD, cardiovascular disease. 
$\mathrm{HbA}_{1 \mathrm{c}}$ cut-off point of 5.8\% (40 mmol/mol). The results suggested that individuals who were true-positive for diabetes had a more unfavorable cardiometabolic risk profile than those who were false-negative (Table 4). Moreover, true-positive individuals had a higher 10-year risk score of CVD than false-negative individuals $(26.7 \%$ vs $24.2 \%, P=0.01)$. In addition, screen-positive individuals exhibited a higher 10-year risk score of CVD than screennegative individuals (Table 4).

\section{Using $\mathrm{HbA}_{1 \mathrm{c}}$ to rule out or rule in diabetes}

Among individuals with undiagnosed diabetes (based on the 1999 WHO criteria) in the exploration dataset, the $\mathrm{HbA}_{1 \mathrm{c}}$ value at the 2.5th percentile was approximately $5.0 \%(31 \mathrm{mmol} / \mathrm{mol})$. Therefore, an $\mathrm{HbA}_{1 \mathrm{c}}$ cut-off point of $5.1 \%$ (32 $\mathrm{mmol} / \mathrm{mol}$ ) was chosen to rule out diabetes. For individuals without diabetes, the $\mathrm{HbA}_{1 \mathrm{c}}$ value at the 97.5th percentile was approximately $6.3 \%$ (45 mmol/mol) [22]; thus, an $\mathrm{HbA}_{1 \mathrm{c}}$ cut-off point of $6.4 \%$ (46 $\mathrm{mmol} / \mathrm{mol}$ ) was selected to rule in diabetes.

When an $\mathrm{HbA}_{1 \mathrm{c}}$ cut-off point of $6.4 \%$ (46 $\left.\mathrm{mmol} / \mathrm{mol}\right)$ was applied, $79.2 \%$ of the diabetes cases from the internal validation dataset and $82.9 \%$ of those from the external validation dataset could be ruled in. Using an $\mathrm{HbA}_{1 \mathrm{c}}$ cut-off point of 5.1\% (32 mmol/ mol), only $4.0 \%$ of the diabetes cases in the internal validation dataset and $3.9 \%$ of those in the external validation dataset could be ruled out. Moreover, if an $\mathrm{HbA}_{1 c}$ cut-off point of $6.4 \%$ (46 $\mathrm{mmol} / \mathrm{mol}$ ) was selected for ruling in diabetes, approximately $25.4 \%$ of the hypertensive individuals with $\mathrm{HbA}_{1 c} \geq 5.8 \%$ (40 $\mathrm{mmol} / \mathrm{mol}$ ) in the internal validation dataset and $27.9 \%$ in the external validation dataset would not require an OGTT for diabetes confirmation.

\section{DISCUSSION}

Our study, which comprised three cross-sectional cohorts, suggests that $\mathrm{HbA}_{1 \mathrm{c}}$ at $5.8 \%(40 \mathrm{mmol} / \mathrm{mol})$ might be the optimal cut-off point for diabetes screening among community-dwellers with hypertension. Individuals who were not diagnosed as having diabetes by $\mathrm{HbA}_{1 \mathrm{c}}$ at $5.8 \%$ (false-negative individuals) had a lower 10-year CVD risk score and a more favorable cardiometabolic risk profile than those correctly identified as having diabetes (true-positive individuals). In addition, $\mathrm{HbA}_{1 \mathrm{c}} \leq 5.1 \%$ (32 mmol/ $\mathrm{mol})$ and $\geq 6.4 \%(46 \mathrm{mmol} / \mathrm{mol})$ may assist in specifying the absence and presence of diabetes, respectively.

The performance of $\mathrm{HbA}_{1 \mathrm{c}}$ in detecting diabetes has received substantial interest [11, 12, 23, 24]. In a systematic review of nine studies, Bennett, et al. [11] suggested that $\mathrm{HbA}_{1 \mathrm{c}}$ at $6.1 \%$
(43 $\mathrm{mmol} / \mathrm{mol}$ ) could be employed as the optimal cut-off point for detecting diabetes but argued that population-specific cutoffs may vary by the population prevalence of diabetes. Partly in accordance with their argument, our study showed that an $\mathrm{HbA}_{1 \mathrm{c}}$ cut-off point of $5.8 \%(40 \mathrm{mmol} / \mathrm{mol})$ provides the best trade-off in screening for diabetes among community-dwellers with hypertension who have a higher prevalence of diabetes than among those without hypertension [2].

The choice of $\mathrm{HbA}_{1 \mathrm{c}}$ at $5.8 \%(40 \mathrm{mmol} / \mathrm{mol})$ as the optimal cut-off point for detecting diabetes in hypertensive individuals could be partly supported by the recent observation of Li, et al. [23] that high-risk populations with $\mathrm{HbA}_{1 \mathrm{c}}$ values of $5.5 \%$ (37 $\mathrm{mmol} / \mathrm{mol}$ )-6.1\% (43 mmol/mol) exhibit an impaired $\beta$-cell function and an ameliorated cardiometabolic risk profile. Moreover, this choice corresponds well with the latest data indicating that the optimal cut-off point of $\mathrm{HbA}_{1 \mathrm{c}}$ for detecting diabetes should be lower than that recommended by the ADA (6.5\%; $48 \mathrm{mmol} /$ mol), especially in Asian countries [24]. Franco, et al. [25] pointed out that the ADA-proposed $\mathrm{HbA}_{1 \mathrm{c}}$ cut-off point was adequate for detecting diabetes in a high-risk population, presenting a sensitivity of $71.3 \%$ and a specificity of $90.5 \%$. This contrasts with our results and those of another study, which showed that an $\mathrm{HbA}_{1 \mathrm{c}}$ cut-off point of $6.5 \%$ (48 mmol/mol) would miss identifying a large proportion of diabetes cases (up to two-thirds) [26].

Our study showed that the accuracy of $\mathrm{HbA}_{1 \mathrm{c}}$ in detecting undiagnosed diabetes would not be affected by sex. Moreover, we found that age may also not influence the accuracy of $\mathrm{HbA}_{\mathrm{Ic}}$ in detecting diabetes, which is consistent with some results of Lee, et al. [27]. Furthermore, our study suggests that neither regular exercise, which reduces the risk of diabetes [28], nor medications, such as statins, which increase the risk of diabetes [29], weaken the performance of $\mathrm{HbA}_{1 \mathrm{c}}$ in detecting diabetes.

Although hypertensive individuals with an $\mathrm{HbA}_{1 c} \geq 5.8 \%$ (40 $\mathrm{mmol} / \mathrm{mol}$ ) exhibited a significantly higher 10-year risk score of CVD than those with an $\mathrm{HbA}_{1 \mathrm{c}}<5.8 \%$ (40 $\mathrm{mmol} / \mathrm{mol}$ ), approximately $24-32 \%$ of the individuals with previously undiagnosed diabetes might be missed by employing the cut-off point of 5.8\% for diabetes detection. This might be because these individuals (false-negative cases) showed a more favorable cardiometabolic risk profile and had a lower risk of CVD than true-positive individuals.

Furthermore, our study demonstrates that an $\mathrm{HbA}_{1 c}$ cut-off point of $5.1 \%(32 \mathrm{mmol} / \mathrm{mol})$ could be applied to rule out diabetes and that the prevalence of diabetes begins to rise when $\mathrm{HbA}_{1 \mathrm{c}}$ reaches 5.2\% (33 mmol/mol)-5.7\% (39 $\mathrm{mmol} / \mathrm{mol}$ ) (data not shown). Thus, hypertensive individuals with an $\mathrm{HbA}_{1 \mathrm{c}}$ of $5.2 \%$ 
(33 mmol $/ \mathrm{mol}$ )-5.7\% (39 mmol/mol) may have an increased risk of developing diabetes and, therefore, need a regular checkup for diabetes and apply certain lifestyle interventions to prevent progression to diabetes [28]. Although $\mathrm{HbA}_{1 c} \geq 5.8 \%$ (40 $\mathrm{mmol} / \mathrm{mol}$ ) showed robust sensitivity in detecting diabetes, this cut-off point could lead to a misdiagnosis rate of up to $25.5 \%$. Thus, subsequent confirmatory testing using OGTT might be necessary for all individuals with an $\mathrm{HbA}_{1 \mathrm{c}} \geq 5.8 \%(40 \mathrm{mmol} / \mathrm{mol})$. However, based on our results that $\mathrm{HbA}_{1 \mathrm{c}} \geq 6.4 \%$ (46 mmol/mol) has sufficient capability to indicate the presence of diabetes, it would be practical to advise that only hypertensive individuals with an $\mathrm{HbA}_{1 \mathrm{c}}$ of $5.8 \%(40 \mathrm{mmol} / \mathrm{mol})-6.3 \%(45 \mathrm{mmol} / \mathrm{mol})$ undergo confirmatory testing.

The strengths of this study include the facts that it enrolled a large and representative sample and used internal and external validation datasets to test the results derived from the exploration population. Moreover, to the best of our knowledge, this is the first study that assessed the performance of $\mathrm{HbA}_{1 \mathrm{c}}$ in community-dwellers with hypertension. However, this study has some limitations. First, diabetes was confirmed only based on a single OGTT. Second, blood pressure was measured only on a single day, while hypertension confirmation requires three blood-pressure measurements on separate days. However, it is somewhat impractical to measure blood pressure in triplicate on different days in a large-scale epidemiological study [30]. Finally, although our sensitivity analysis suggests that the presence of anemia did not significantly influence the performance of $\mathrm{HbA}_{1 c}$, other conditions, including hemoglobinopathies and glucose-6-phosphate dehydrogenase deficiency, may affect the relationship between $\mathrm{HbA}_{1 \mathrm{c}}$ and diabetes detection [17].

In conclusion, this study suggests that $\mathrm{HbA}_{1 \mathrm{c}}$ has reasonable diagnostic efficacy for detecting diabetes in community-dwellers with hypertension and that $\mathrm{HbA}_{1 \mathrm{c}} \geq 5.8 \%$ (40 $\mathrm{mmol} / \mathrm{mol}$ ) could be employed for screening for diabetes. $\mathrm{HbA}_{1 \mathrm{c}} \leq 5.1 \%$ (32 mmol/ $\mathrm{mol}$ ) and $\geq 6.4 \%$ (46 mmol/mol) may specify the absence and presence of diabetes in this population, respectively. Hypertensive individuals with $\mathrm{HbA}_{1 \mathrm{c}}$ between $5.2 \%$ (33 mmol/mol)-5.7\% (39 mmol/mol) would benefit from ongoing and regular check-ups for diabetes, while those with $\mathrm{HbA}_{1 \mathrm{c}}$ between $5.8 \%$ (40 mmol/ $\mathrm{mol})-6.3 \%$ (45 $\mathrm{mmol} / \mathrm{mol})$ may require confirmatory testing.

\section{ACKNOWLEDGEMENTS}

None.

\section{AUTHOR CONTRIBUTIONS}

$S Q, Z D, B W, H G$, and ZS designed this study and drafted the manuscript. SQ, ZD, WL, and JC contributed to analytical method standardization. SQ, HW, JL, MC, BW, HG, and ZS acquired and analyzed the data. SQ, ZD, JC, HW, JL, MC, and HG carried out the statistical analysis. WL, JC, MC, BW, HG, and ZL reviewed and edited the manuscript. All authors approved the final manuscript.

\section{CONFLICTS OF INTEREST}

No potential conflicts of interest relevant to this paper were reported.

\section{RESEARCH FUNDING}

This work was supported by the National Key R\&D Program of China (grant No. 2016YFC1305700), the National Key Scientific Instrument and Equipment Development Project of China (grant No. 51627808), the Nanjing Special Fund for Health Science and Technology Development (grant No. YKK18261), and the Excellence Project Funds of Southeast University (grant No. 119 0001801). The funders had no role in the design of the study; collection, analysis, and interpretation of data; or in writing or submitting this manuscript.

\section{ORCID}

Shanhu Qiu

https://orcid.org/0000-0003-2597-3856

Ziwei Du

Wei Li

Juan Chen

Hang Wu

Jingbao Liu

Min Cai

Bei Wang

Haijian Guo

Zilin Sun https://orcid.org/0000-0002-2835-8376 https://orcid.org/0000-0002-6272-6419 https://orcid.org/0000-0002-8069-0675 https://orcid.org/0000-0003-4431-5349 https://orcid.org/0000-0002-2932-0724 https://orcid.org/0000-0003-1468-2818 https://orcid.org/0000-0001-5940-4075 https://orcid.org/0000-0002-9223-1302 https://orcid.org/0000-0001-7936-0196

\section{REFERENCES}

1. Mills KT, Bundy JD, Kelly TN, Reed JE, Kearney PM, Reynolds K, et al Global disparities of hypertension prevalence and control: a systematic analysis of population-based studies from 90 countries. Circulation 2016; 134:441-50

2. Lu J, Lu Y, Wang X, Li X, Linderman GC, Wu C, et al. Prevalence, aware- 
ness, treatment, and control of hypertension in China: data from 1.7 million adults in a population-based screening study (China PEACE Million Persons Project). Lancet 2017;390:2549-58.

3. Tsimihodimos V, Gonzalez-Villalpando C, Meigs JB, Ferrannini E. Hypertension and diabetes mellitus: coprediction and time trajectories. Hypertension 2018;71:422-8.

4. Li T, Chen S, Guo X, Yang J, Sun Y. Impact of hypertension with or without diabetes on left ventricular remodeling in rural Chinese population: a cross-sectional study. BMC Cardiovasc Disord 2017;17:206.

5. Thomopoulos C, Parati G, Zanchetti A. Effects of blood-pressure-lowering treatment on outcome incidence in hypertension: 10-Should blood pressure management differ in hypertensive patients with and without diabetes mellitus? Overview and meta-analyses of randomized trials. J Hypertens 2017;35:922-44.

6. Oh JY, Allison MA, Barrett-Connor E. Different impacts of hypertension and diabetes mellitus on all-cause and cardiovascular mortality in community-dwelling older adults: the Rancho Bernardo Study. J Hypertens 2017;35:55-62.

7. Zafari N, Asgari S, Lotfaliany M, Hadaegh A, Azizi F, Hadaegh F. Impact of hypertension versus diabetes on cardiovascular and all-cause mortality in Iranian older adults: results of 14 years of follow-up. Sci Rep 2017; 7:14220.

8. Kim MJ, Lim NK, Choi SJ, Park HY. Hypertension is an independent risk factor for type 2 diabetes: the Korean genome and epidemiology study. Hypertens Res 2015;38:783-9.

9. Tatsumi Y, Morimoto A, Asayama K, Sonoda N, Miyamatsu N, Ohno Y, et al. Risk of developing type 2 diabetes according to blood pressure levels and presence or absence of hypertensive treatment: the Saku study. Hypertens Res 2019;42:105-13.

10. American Diabetes Association. Diagnosis and classification of diabetes mellitus. Diabetes Care 2010;33(S1):S62-9.

11. Bennett CM, Guo M, Dharmage SC. HbAlc as a screening tool for detection of Type 2 diabetes: a systematic review. Diabet Med 2007;24: 333-43.

12. Bertran EA, Berlie HD, Taylor A, Divine G, Jaber LA. Diagnostic performance of $\mathrm{HbAlc}$ for diabetes in Arab vs. European populations: a systematic review and meta-analysis. Diabet Med 2017;34:156-66.

13. Maesa JM, Fernandez-Riejos P, Gonzalez-Rodriguez C, Sanchez-Margalet $\mathrm{V}$. Screening for gestational diabetes mellitus by measuring glycated hemoglobin can reduce the use of the glucose challenge test. Ann Lab Med 2019;39:524-9.

14. Ehehalt S, Wiegand S, Körner A, Schweizer R, Liesenkötter KP, Partsch $\mathrm{CJ}$, et al. Diabetes screening in overweight and obese children and adolescents: choosing the right test. Eur J Pediatr 2017;176:89-97.

15. Li W, Xie B, Qiu S, Huang X, Chen J, Wang X, et al. Non-lab and semilab algorithms for screening undiagnosed diabetes: a cross-sectional study. EBioMedicine 2018;35:307-16.

16. Bossuyt PM, Reitsma JB, Bruns DE, Gatsonis CA, Glasziou PP, Irwig L, et al. STARD 2015: an updated list of essential items for reporting diagnostic accuracy studies. BMJ 2015;351:h5527.

17. Weykamp C. HbA1c: a review of analytical and clinical aspects. Ann Lab Med 2013;33:393-400.

18. Gabir MM, Hanson RL, Dabelea D, Imperatore G, Roumain J, Bennett $\mathrm{PH}$, et al. The 1997 American Diabetes Association and 1999 World Health Organization criteria for hyperglycemia in the diagnosis and prediction of diabetes. Diabetes Care 2000;23:1108-12.

19. D’Agostino RB Sr, Vasan RS, Pencina MJ, Wolf PA, Cobain M, Massaro JM, et al. General cardiovascular risk profile for use in primary care: the Framingham Heart Study. Circulation 2008;117:743-53.

20. Safari S, Baratloo A, Elfil M, Negida A. Evidence based emergency medicine; part 5 receiver operating curve and area under the curve. Emerg (Tehran) 2016;4:111-3.

21. Altman DG and Bland JM. Interaction revisited: the difference between two estimates. BMJ 2003;326:219.

22. Lu ZX, Walker KZ, O'Dea K, Sikaris KA, Shaw JE. A1C for screening and diagnosis of type 2 diabetes in routine clinical practice. Diabetes Care 2010;33:817-9.

23. Li G, Han L, Wang Y, Zhao Y, Li Y, Fu J, et al. Evaluation of ADA HbAlc criteria in the diagnosis of pre-diabetes and diabetes in a population of Chinese adolescents and young adults at high risk for diabetes: a crosssectional study. BMJ Open 2018;8:e020665.

24. Hoyer A, Rathmann W, Kuss O. Utility of HbAlc and fasting plasma glucose for screening of Type 2 diabetes: a meta-analysis of full ROC curves. Diabet Med 2018;35:317-22.

25. Franco LJ, Dal Fabbro AL, Martinez EZ, Sartorelli DS, Silva AS, Soares $\mathrm{LP}$, et al. Performance of glycated haemoglobin $(\mathrm{HbAlc})$ as a screening test for diabetes and impaired glucose tolerance (IGT) in a high risk population-the Brazilian Xavante Indians. Diabetes Res Clin Pract 2014;106: 337-42.

26. Peter A, Fritsche A, Stefan N, Heni M, Häring HU, Schleicher E. Diagnostic value of hemoglobin A1c for type 2 diabetes mellitus in a population at risk. Exp Clin Endocrinol Diabetes 2011;119:234-7.

27. Lee H, Oh JY, Sung YA, Kim DJ, Kim SH, Kim SG, et al. Optimal hemoglobin A1C cutoff value for diagnosing type 2 diabetes mellitus in Korean adults. Diabetes Res Clin Pract 2013;99:231-6.

28. Smith AD, Crippa A, Woodcock J, Brage S. Physical activity and incident type 2 diabetes mellitus: a systematic review and dose-response meta-analysis of prospective cohort studies. Diabetologia 2016;59:252745.

29. Casula M, Mozzanica F, Scotti L, Tragni E, Pirillo A, Corrao G, et al. Statin use and risk of new-onset diabetes: a meta-analysis of observational studies. Nutr Metab Cardiovasc Dis 2017;27:396-406.

30. Di Bonito P, Valerio G, Pacifico L, Chiesa C, Invitti C, Morandi A, et al. A new index to simplify the screening of hypertension in overweight or obese youth. Nutr Metab Cardiovasc Dis 2017;27:830-5. 